\title{
Analysis of the impact of economic growth factors to resources and environment in Jiangsu Province -- Based on Commoner model
}

\author{
Min Zhang ${ }^{\mathrm{a}}$ \\ Department of Management, Jincheng College, Nanjing University of Aeronautics \& Astronautics ,China
}

\begin{abstract}
In order to response to the increasingly polluted environment, maintain sustainable economic and social development in Jiangsu province, the author calculated the index of the resource environment in Jiangsu, using LMDI(logarithmic-mean Divisia index) decomposition method based on the Commoner model(we can see from formula(2),(5),(6)\&(7)), to reflect the three major influencing factors of cumulative effects. In table 2 and figure 3 , the research results show the expansion of the size of economy and growth of population make resources consumption increase and environmental pollution aggravate, while technological progress reduce the pressure of resources and environment. According to the findings, the paper proposes the policy recommendations, such as develop circular economy, promote technological innovation and strengthen regional cooperation mechanism and so on to reduce the environmental pollution while economic developing. These will be useful to the policymakers. Keywords. Economic growth factors; Resources and environment; Commoner model; LMDI (logarithmic-mean Divisia index )
\end{abstract}

\section{Introduction}

In the book Process Of Economic Growth [1], American economist Rostow divided the economic growth into six stages: traditional society, create precondition for fast developing phase, fast developing phase, to mature, the phase of high mass consumption and the pursuit of quality of life. The fast developing stage is one of the most important mutations, there are three conditions: high accumulation rate and set up a leading department and appropriate system guarantee. When meets the three conditions, the economy will develop fast, then the economic departments gradually become strong, enter into the phase of mature. The mature stage is the period of a society to use the modern science and technology ${ }^{a}$ Corresponding author:jshalf@163.com effectively to allocate resources.

More than 20 years of development in Jiangsu generally experienced the stage Rostow had described, which is in the transitional period being pushed off from the fast developing to the mature stage. Jiangsu is a major economic province; its economic development occupies an important position in the whole country. Jiangsu province' GDP in 2014 [2] reached 6.50883 trillion yuan, accounting for $10.2 \%$ of national GDP, ranks second following Guangdong province. Per capita GDP is 81874 yuan, total retail sales of social consumer goods are 2.3209 trillion yuan, accounting for $8.8 \%$ of the country. The rapid economic growth in Jiangsu is established on the basis of a large number of resources such as land, 
water, minerals and energy resources. Economic development consume large resources, at the same time, it can also damage the natural resources and ecological environment.

Through the studies of Jiangsu economy, population, environment pollution and so on, the paper will explore the coordinate, sustainable development path of economic, ecological and social.

\section{Analysis of resources and environment in Jiangsu province}

After more than 20 years of rapid development, marked by per capita GDP reaching $\$ 3000$, economic and social development in Jiangsu province's has entered a new stage. During this period, development is facing many opportunities meanwhile severe resource constraints and environmental pressure. Jiangsu has created accounting for more than $10 \%$ of the country's economy with about $1.1 \%$ of the country's land area, $5.7 \%$ of the population. The speeding up of industrialization has brought the increase of energy consumption for production of coal, natural gas, crude oil, more than $90 \%$ of these resources rely on outsourcing, which makes the energy cost be larger [3].

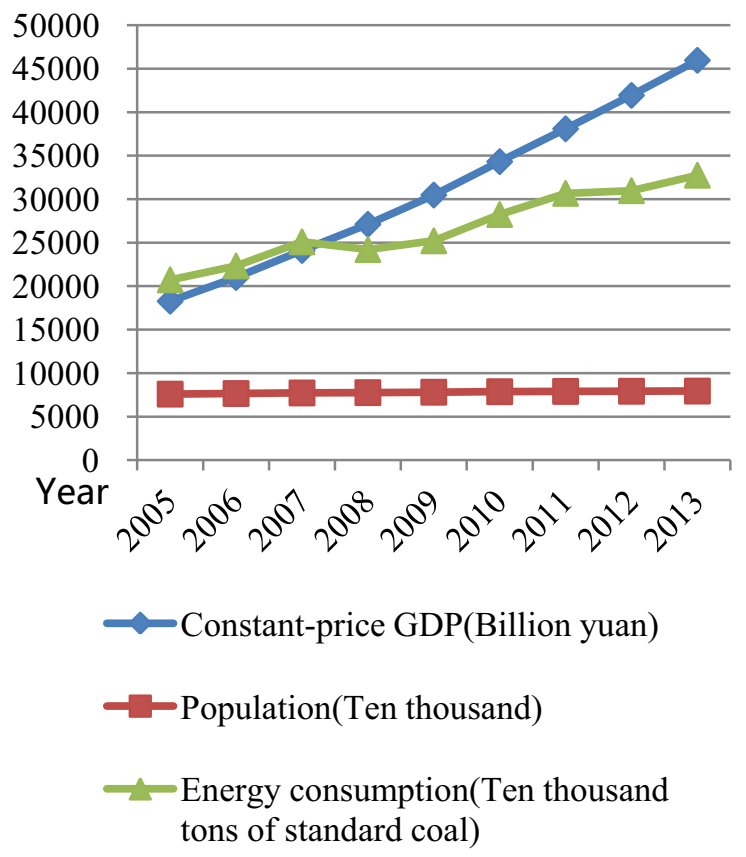

Figure1. The trend of population, GDP, energy consumption in Jiangsu Province from 2005 to 2013

As can be seen from the figure 1, during the eight years, GDP shows growth trend in Jiangsu province from
1.827212 trillion yuan to 4.596518 trillion yuan, the annual average growth rate is $12.5 \%$. Accompanying With the development of economy, energy consumption is also growing from 207.2374 million tons to 327.5661

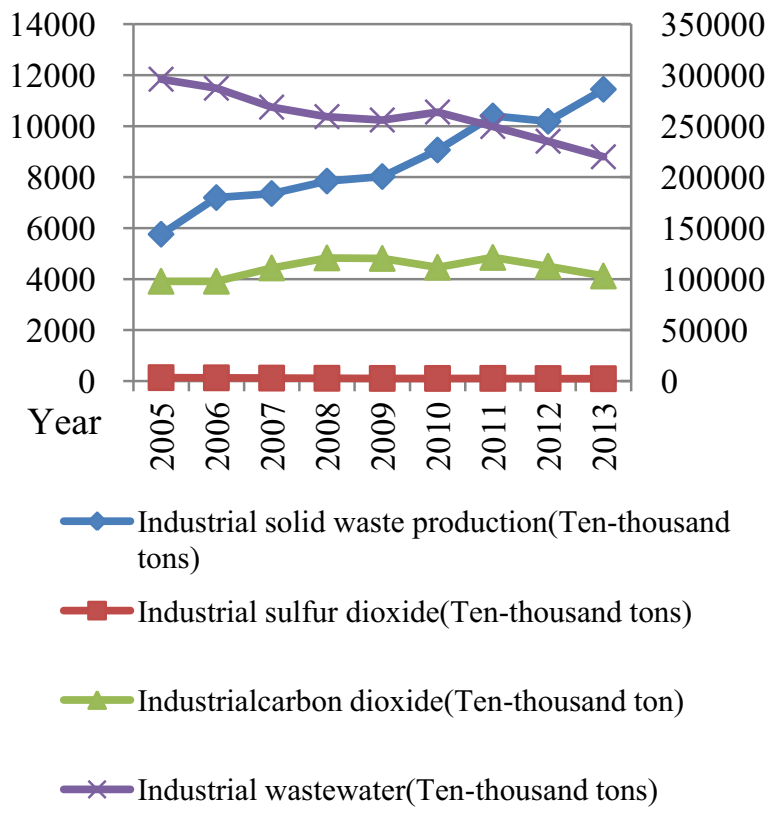

Figure2. The trend of Three Industrial Wastes and the industrial carbon emissions in Jiangsu province

million tons of standard coal, 1.58 times higher than in 2005 , the average annual growth rate is $6 \%$. While population growth in Jiangsu province is slow, increasing by only 1.05 times.

Along with the economic development, energy consumption brings environmental pollution. From the figure 2 we can see, in addition to the emissions of industrial waste water is decreasing; the other three indicators are all increasing. Among them, the most significant growth is the industrial solid waste emissions, from 57.57 million tons to 109.165 million tons, increased nearly $90 \%$.

\section{Introduction of Commoner Model and the data sources}

\subsection{Introduction of Commoner Model}

Commoner[4,5]believed that environmental quality is mainly influenced by three factors: (1) Population growth factor, which is mainly reflected by population size; (2) Economic growth factor, it is mainly reflected by per capita output; (3) Technical progress factor, mainly 
reflected by pollution emissions of the unit production value

I.e., the emissions of pollutants quantity $=$ population

* (production/population) * (emissions/production),

specifically expressed as:

$$
I=\frac{G}{P} \times P \times \frac{I}{G}
$$

In the equation, I indicates pollution emissions, $\mathrm{P}$ shows total population, G indicates GDP. On the right side of the equation, the first one means economic size effect, the second indicates effect of population growth, the third one shows effect of technological progress.

Based on factorization analysis type(1), there will be three results: if the effect of some factor to the environment is positive number, it shows the elements will increase the environmental stress; If the effect of some factor to the environment is negative number, it indicates the factor reducing the pressure of environment, conducive to the coordinated development; If the effect of some factor to the environment is zero, then it indicates that the elements do not produce environmental pressures.

On the basis of The Commoner Model, using logarithmic-mean Divisia index (LMDI) [6,7] to analyze these three elements. LMDI decomposition method is one complete decomposition method[8], won't produce residual, and easy to be transformed between multiplication and addition decomposition form, any kind of selection is no difference. This paper uses the additive form. Specific as follows:

$$
I=E \times P \times C
$$

Among them, $E=G / P$ indicates the size of the economy, $\mathrm{P}$ shows population growth effect, $\mathrm{C}=\mathrm{I} / \mathrm{G}$ indicates technical progress effect.

$$
\Delta I=I^{T}-I^{0}=\Delta I_{E}+\Delta I_{P}+\Delta I_{C}
$$

$$
\Delta I_{X}=\sum \frac{I_{i}^{t}-I_{0}^{t}}{\ln I_{i}^{t}-\ln I_{0}^{t}} \ln \frac{X_{i}^{t}}{X_{0}^{t}}
$$

In formula (3), $\Delta \mathrm{I}$ means emissions change from $0 \sim \mathrm{t}$ years, $\mathrm{I}^{\mathrm{T}}$ means the pollution emissions of $\mathrm{t}$ year, $\mathrm{I}^{0}$ means the pollution emissions of 0 year. $\Delta \mathrm{I}_{\mathrm{E}}$ Shows the impact of economic size on pollution emissions; $\Delta \mathrm{I}_{\mathrm{P}}$ means the influence of population growth on pollution emission; $\Delta \mathrm{I}_{\mathrm{C}}$ shows the influence of technology progress on pollution emission. In formula (4), $\Delta \mathrm{I}_{\mathrm{X}}$ indicates the effect value that change of various factors on pollution emissions.

According to Ang's [9]LMDI decomposition method, the right side of type (3) can be expressed as:

$$
\begin{aligned}
& \Delta I_{E}=\sum \frac{I_{i}^{t}-I_{0}^{t}}{\ln I_{i}^{t}-\ln I_{0}^{t}} \ln \frac{E_{i}^{t}}{E_{0}^{t}} \\
& \Delta I_{P}=\sum \frac{I_{i}^{t}-I_{0}^{t}}{\ln I_{i}^{t}-\ln I_{0}^{t}} \ln \frac{P_{i}^{t}}{P_{0}^{t}} \\
& \Delta I_{C}=\sum \frac{I_{i}^{t}-I_{0}^{t}}{\ln I_{i}^{t}-\ln I_{0}^{t}} \ln \frac{C_{i}^{t}}{C_{0}^{t}}
\end{aligned}
$$

\subsection{Date sources}

We choose the data of Jiangsu Province from year 2005 to 2013 to study. Among them, the data about GDP, population, energy consumption, industrial three wastes are derived from the corresponding year of Jiangsu Statistical Yearbook [10], and the industrial carbon emissions data are from the balance of energy terminal consumption data which are in the China Energy Statistical Yearbook [11], calculating according to coefficient of the carbon conversion of various energy consumption from table 1 [3]. And GDP is transformed by the conversion coefficient into constant price GDP in 2005 according to Jiangsu Statistical Yearbook.

Table 1 .The carbon conversion coefficient of three energy consumption

\begin{tabular}{|c|c|c|c|}
\hline Data sources & $\begin{array}{c}\text { Coal consumption } \\
\text { coefficient of carbon } \\
\text { emissions }\end{array}$ & $\begin{array}{c}\text { Oil consumption } \\
\text { coefficient of carbon } \\
\text { emissions }\end{array}$ & $\begin{array}{c}\text { Natural gas consumption } \\
\text { coefficient of carbon } \\
\text { emissions }\end{array}$ \\
\hline DOE/EIA & 0.702 & 0.478 & 0.389 \\
\hline IEEJ & 0.756 & 0.586 & 0.449 \\
\hline CNSTI & 0.728 & 0.583 & 0.409 \\
\hline mean value & 0.728 & 0.549 & 0.416 \\
\hline
\end{tabular}




\section{Analysis of the influence factors of resources and environment}

It's calculated according to the data obtained above for each influence factor's contribution to the pollution emissions, the results are shown in table 2.

Table 2. The cumulative effects of various factors from 2005 to 2013(units, ten thousand tons)

\begin{tabular}{|c|c|c|c|}
\hline Year & $\begin{array}{c}\text { Effect of } \\
\text { economic } \\
\text { size }\end{array}$ & $\begin{array}{c}\text { Effect of } \\
\text { population } \\
\text { growth }\end{array}$ & $\begin{array}{c}\text { Effect of } \\
\text { technology } \\
\text { progress }\end{array}$ \\
\hline 2005 & - & - & - \\
\hline 2006 & 39287.16 & 2672.25 & -49327.20 \\
\hline 2007 & 75965.15 & 5162.14 & -106423.05 \\
\hline 2008 & 107361.83 & 6552.12 & -147634.00 \\
\hline 2009 & 138534.62 & 8276.16 & -183682.05 \\
\hline 2010 & 173047.75 & 10598.86 & -212022.73 \\
\hline 2011 & 197856.54 & 11427.12 & -250134.77 \\
\hline 2012 & 218256.27 & 11850.71 & -285919.67 \\
\hline 2013 & 236115.24 & 12178.93 & -318539.20 \\
\hline mean & 148303.07 & 8589.79 & -194210.34 \\
\hline value & & & \\
\hline
\end{tabular}

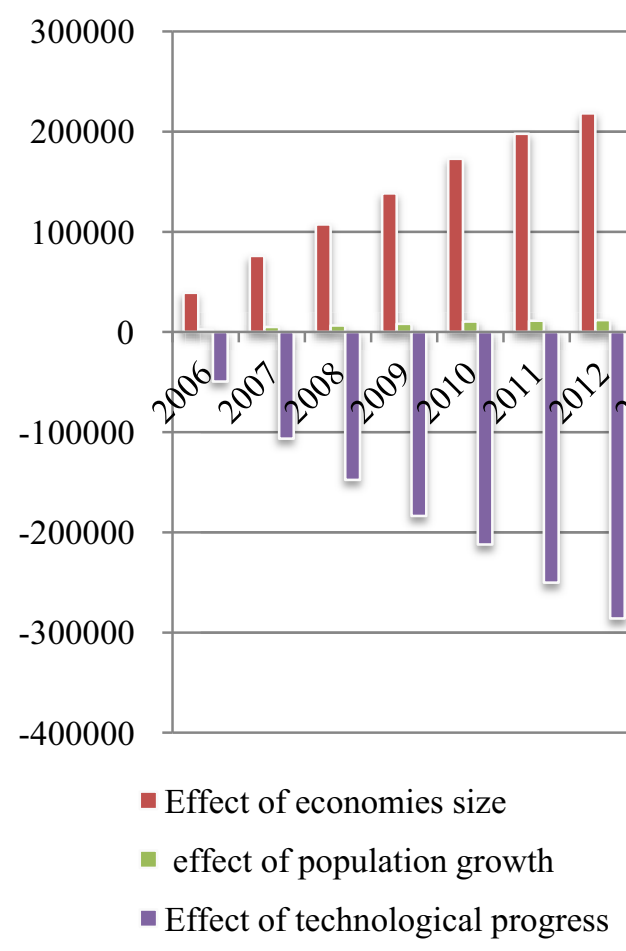

Figure3. The cumulative effects of various factors of each year

It can be seen from table 2 and figure 3 , the decomposition results show that among the three influence factors in the study, the effect of economic size and population growth in 2006-2013 is positive, these two factors have made the environmental pressure increased heavily, and the effect of technical progress during this period is negative, indicating this factor reducing the pressure on resources and environment, that is, this factor has inhibition effects on resources and environment.

\subsection{Analysis of influence of economic size to resources and environment}

Panayotou [12,13]put forward Environmental Kuznets Theory in 1993, he thought that the environment pollution will experience from high to low along with the development of a country's economy, deteriorating at first and then gradually improving, it will appear in the form of inverted u-shaped. It also means that: on the one hand, economic development would lead to pollution emissions, but on the other hand, the development of economy makes people's living standards improve, the requirements for environmental quality increase, investment of protection money by the state is becoming more and more abundant. Therefore, economic development will benefit to improve the environment.

The table 2 shows that the effect of economic size in Jiangsu province from 2006 to 2013 is positive, rising year by year, it also indicates the expansion of economic size has increased the resource consumption and caused the increase of environmental pollution. The effect of economic size plays a leading role.

\subsection{Analysis of influence of population scale to resources and environment}

Population growth will inevitably require the expansion of the size of economic activity to keep increasing requirements of material and spiritual products. Under the condition of existing resources, there is also a sustainable population limits. Shown in Figure 1, the total population in Jiangsu Province is slow growth, and the growth of population contributed averages 85.8979 million tons of environment pollution. The increase of population size brings high pressure of resources, ecological environment, but it's not a leading role. 


\subsection{Analysis of influence of technical progress to resources and environment}

Simon [4] proposed that, technological progress can develop a new industry, increase the ability of conversion from raw material to product. The transformation of old industrial chain and improve the energy efficiency. Therefore, it must rely on technological progress to reduce resource consumption and improve the ecological environment.

We generally think that technological progress is helpful for us to achieve the sustainable development; it is key point to overcome the shortage of resources and environmental pollution problems by economic development. In fact, the relevant data analysis of Jiangsu province can also prove that the calculation results of technology progress effect are negative, indicating technological progress reduce the pressure on the environment and promote the coordinated development of economy and environment.

\section{Conclusion}

In this paper, by the calculation of GDP, pollution emissions and etc. of Jiangsu province, we find that from 2005 to 2013, both expanded economies of scale and population growth brought pressure to environmental resources, while technological progress decreased pressure of environment. In order to realize the sustainable development of economic and society of Jiangsu province, we need do as these if we want to reduce environmental pollution accompany with rapid economic development [14,15]:

(1)Make known the concept of cleaner production, reduce the waste and pollutants from fundamental source and encourage enterprises to produce green products, set up and promote ecological economic demonstration area; (2) Develop circular economy, transform the mode of economic growth. Promote further measures on the strategic adjustment of industrial structure, achieve the economic growth by manufacturing and services; Increase investment in new energy and environmental protection and energy saving products. (3) Promote technological innovation, increase investment in regional environmental protection, encourage enterprises to improve product process or assembly line, make the enterprise reduce pollution levels at the same time achieve a win-win economic and ecological environment benefits. (4) Strengthen the regional cooperation and promote the pollution prevention actively. Jiangsu province should strengthen the regional cooperation mechanism to achieve the greatest degree of economic green growth.

\section{References}

1.Jiangsu province bureau's Web site, http://www.jssb.gov.cn/goveinfo/xxgkml/ywgz/dtyw/200 606/t20060626_8015.html

2.Jiangsu Statistical Yearbook, http://www.jssb.gov.cn/2015nj/indexc.htm

3. S.S.Lin, S\&T Management Research, 13:62-65(2013)

4. H.A.Hu. Liaoning Normal University,(2013)

5. G.Z.Lee, China Economic Publishing House,(2007)

6. H.J. Yang, M.Y.Lee, H.Q.Liu, 02:125-129,(2014)

7. P. Fernández González,M. Landajo,M.J. Presno. Energy, 73(2014)

8. M.Sun, Jilin University,(2010)

9. B. W. Ang, Energy Policy, 32(9):1131-1139,(2004)

10. Jiangsu Statistical Yearbook. http://www.jssb.gov.cn/tjxxgk/tjsj/tjnq/jstjnj2015/index_2 12.html

11. China Energy Statistical Yearbook. http://epub.cnki.net/kns/brief/default_result.aspx

12. T. Wang, Yangzhou University, (2014)

13. Panayoutou. Working Paper WP238, Technoloty and Employment Programme, Geneva, (1993)

14. J. Bollen, Corjan Brink. Energy Economics, 46(2014)

15. J.Bollen.Technological Forecasting \& Social Change, 90(2015)

Sources of funds: Excellent course of statistics of Jingcheng college,(2014-J-10) 